\author{
Сизова Ю.В., \\ Бурлакова О.С., \\ Пичурина Н.^.
}

\begin{abstract}
Федеральное казенное учреждение зАравоохранения «Ростовский-на-Аону орАена Трудового Красного Знамени научно-исследовательский противочумный институт" ФеАеральной службы по налзору в сфере защиты прав потребителей и благополучия человека, 344002, г. Ростов-на-Аону, Российская Федерация
\end{abstract}

Обеспечение биологической безопасности является важной международной проблемой и обусловливает актуальность регулярной подготовки специалистов по этому направлению.

Цель исследования - оценка опыта подготовки специалистов по биологической безопасности.

Материал и методы. Законодательные, нормативно-методические документы, публикации, учебные программы повышения квалификации и профессиональной переподготовки в области подготовки специалистов по биологической безопасности работ с возбудителями особо опасных инфекций с использованием аналитического метода.

Результаты и обсуждение. Система подготовки по биологической безопасности с учетом эпидемиологических рисков изменяется в соответствии с требованиями, предъявляемыми к квалификации специалистов, переходом на дистанционную форму и сокращением времени обучения.

Заключение. Имеющаяся система подготовки специалистов по вопросам обеспечения биологической безопасности показывает достаточно высокую эффективность, но нуждается в разработке новых программ, внедрении новых форм обучения и регулярной оперативной актуализации в связи с высокой изменчивостью эпидемиологической обстановки в стране и в мире.

Финансирование. Исследование не имело финансовой поддержки. Конфликт интересов. Авторы заявляют об отсутствии конфликта интересов.

Вклад авторов. Концепция исследования, сбор и обработка материала - Сизова Ю.В.; написание текста - Сизова Ю.В., Бурлакова 0.С.; редактирование, утверждение окончательного варианта статьи - Сизова Ю.В., Бурлакова 0.С., Пичурина Н.Л.

Для цитирования: Сизова Ю.В., Бурлакова О.С., Пичурина Н.Л. Опыт подготовки специалистов по биологической безопасности // Инфекционные болезни: новости, мнения, обучение. 2021. T. 10, № 4. С. 115-119. D0I: https://doi.org/10.33029/23053496-2021-10-4-115-119

Статья поступила в редакцию 14.06.2021. Принята в печать 01.10.2021.
Ключевье слова: биологическая безопасность, подготовка специалистов, непрерывное медицинское образование, повышение квалификации

\title{
Experience in training specialists in biological safety
}

Sizova Yu.V., Burlakova O.S., Pichurina N.L.
Rostov-on-Don Plague Control Researsh Institute of the Federal Service for Surveillance in the Sphere of Consumers Rights Protection and Human Welfare, 344002, Rostov-on-Don, Russian Federation

Ensuring biosafety is an important international problem and makes it necessary to regularly train specialists in biosafety issues.

Research objective. Assessment of the experience of training specialists in biological safety.

Material and methods. Legislative, regulatory and methodological documents, publications, training programs for advanced training and professional retraining in the field of training specialists in biological safety of work with pathogens of particularly dangerous infections using the analytical method.

Results. The system of training in biological safety, taking into account epidemiological risks, is changing in accordance with the requirements for the qualification of specialists, the transition to a remote form and the reduction of training time. 
Conclusion. The existing system of training specialists in biosafety issues shows quite high efficiency, but it needs to develop new programs, introduce new forms of training and regularly update them due to the high variability of the epidemiological situation in the country and the world.

Funding. The study had no sponsor support.

Conflict of interest. The authors declare no conflict of interest.

Contribution. The concept of research, the collection and processing of material - Sizova Yu.V.; writing a text - Sizova Yu.V., Burlakova 0.S.; editing, approval of the final version of the article - Sizova Yu.V., Burlakova 0.S., Pichurina N.L.

For citation: Sizova Yu.V., Burlakova 0.S., Pichurina N.L. Experience in training specialists in biological safety. Infektsionnye bolezni: novosti, mneniya, obuchenie [Infectious Diseases: News, Opinions, Training]. 2021; 10 (4): 115-9. D0I: https://doi. org/10.33029/2305-3496-2021-10-4-115-119 (in Russian)

Received 14.06.2021. Accepted 01.10.2021.
Keywords:

biological safety, training of specialists, continuing medical education, advanced training
0 беспечение биологической безопасности, особенно в свете возможности применения биологического оружия, является важной международной проблемой. Понятие «биологическая безопасность» включает состояние защищенности населения и окружающей среды от воздействия опасных биологических факторов, в качестве которых могут выступать событие, условие, свойство, эпидемический, эпизоотический, эпифитотический процессы или их комбинации, являющиеся причиной возможного воздействия патогенных биологических агентов (ПБА), паразитических организмов и содержащих их объектов, способных нанести вред здоровью человека и (или) окружающей среде, при котором обеспечивается допустимый уровень биологического риска [1-3].

Под ПБА понимают не только микроорганизмы, вирусы, белковоподобные инфекционные частицы (прионы), яды биологического происхождения (токсины) и иные биологические агенты, в том числе созданные в результате генетических манипуляций, применения технологий синтетической биологии и другой направленной деятельности, способные вызывать патологический процесс в организме человека, но и биологические материалы, в которых могут содержаться перечисленные патогены.

Многовариантность современных угроз в области биологической безопасности диктует необходимость регулярной подготовки медицинских кадров, способных работать в условиях чрезвычайной ситуации (ЧС). В связи с этим организация и проведение обучения по вопросам обеспечения биологической безопасности, диагностики актуальных инфекционных болезней и оценке готовности к отражению внешних и внутренних эпидемиологических угроз является одним из важнейших направлений. Реализация таких программ обучения необходимая часть подготовки специалистов [4].

Цель исследования - оценка опыта подготовки специалистов по биологической безопасности.

\section{Материал и методы}

Материал для исследования - законодательные и нормативно-методические документы, публикации, учебные программы повышения квалификации и профессиональной переподготовки в области подготовки специалистов по биологической безопасности работ с возбудителями особо опасных инфекций (00И). Использован аналитический метод.

\section{Результаты и обсужкение}

Одной из основных задач отечественного здравоохранения является непрерывное медицинское образование для обеспечения постоянного повышения квалификации и роста профессионализма специалистов с высшим и средним специальным медицинским образованием с применением современных подходов к обучению, в том числе дистанционных технологий. В сети Интернет представлены разнообразные дистанционные образовательные циклы по любой специальности, но их использование должно быть в комплексе с очным обучением для приобретения специалистами практических навыков.

Обучение по разделу «00И и обеспечение биологической безопасности» необходимо проходить в специализированных учреждениях Роспотребнадзора, таких как противочумные институты и станции, поскольку в соответствии с действующей нормативно-методической документацией РФ к работе с ПБА, особенно I-II групп патогенности, допускаются специалисты, прошедшие очную переподготовку по программам дополнительного профессионального образования для приобретения навыков безопасной работы с возбудителями ООИ $[5,6]$.

В связи с этим каждый образовательный цикл профессиональной переподготовки по специальностям: 32.08.14 «Бактериология», 32.08.12 «Эпидемиология» и 31.02 .03 «Лабораторная диагностика» начинается с модуля, посвященного биологической безопасности. Этот модуль предусматривает освоение нормативной документации по безопасной работе с ПБА, а также приобретение навыков обеспечения биологической безопасности при выполнении практических манипуляций. Освоение практических навыков включает 3 этапа: сначала обучающиеся работают с незараженным материалом, затем с использованием ПБА III-IV групп патогенности и только после этого - с микроорганизмами I-II групп патогенности. Во всех учреждениях противочумной системы занятия проходят под контролем опытных высококвалифицированных сотрудников организаций в помещениях, полностью отвечающих требованиям нормативных документов [7].

Повышение квалификации специалистов по вопросам биологической безопасности проводится по программе объемом 137 ч, разработанной совместно специалистами всех противочумных институтов и утвержденной их руководителями. Про- 
грамма включает 2 модуля: модуль 1 - биобезопасность и биозащита при работе с ПБА, в котором слушатели отрабатывают теоретические аспекты и проводятся практические занятия; модуль 2 - противодействие биологическому терроризму, в рамках которого проводят ознакомление с проблемой биологического терроризма на современном этапе и методами противодействия, изучают вероятные биологические агенты и принципы биологической безопасности в очагах 00И.

Цель программы - совершенствование профессиональных компетенций, необходимых для профессиональной деятельности специалистов с высшим образованием по вопросам оценки биологической опасности, обеспечения безопасности при организации и проведении работ с ПБА, в том числе в очагах 00И.

Учебная программа предусматривает формирование:

- теоретических знаний, умений и навыков по обеспечению системы биобезопасности и устранению факторов риска нарушения ее функционирования при организации и проведении работ с патогенами в учреждении, лаборатории и очагах 00И, включая осуществление контрольных мероприятий; по оценке уровня безопасности потенциально опасных объектов и разных видов работ с ПБА;

- теоретических знаний по эпидемиологии, этиологии, лабораторной диагностике, клинической картине, лечению, специфической и неспецифической профилактике инфекционных болезней, требующих проведения мероприятий по санитарной охране территории России, включая 00И, и социально значимых инфекционных болезней;

- теоретических знаний и умений по планированию санитарно-противоэпидемических (профилактических) мероприятий, направленных на предотвращение и ликвидацию ЧС в области санитарно-эпидемиологического благополучия населения, в том числе возникающих в результате биологических террористических актов;

- теоретических знаний, умений и навыков выбора, применения и обеззараживания средств индивидуальной защиты (СИЗ), регламентированных для работ с ПБА в лаборатории и очаге инфекции;

- теоретических знаний и умений организации и проведения контроля биологической защиты объектов (подразделений), осуществляющих работы с ПБА.

В связи с переходом на непрерывное медицинское образование рекомендуемый ежегодный объем освоения программ повышения квалификации - 36 зачетных единиц трудоемкости, что обусловило актуальность разработки новых учебных программ объемом 36 ч, учитывающих индивидуальные потребности различных категорий слушателей [8].

Например, в рамках подготовки к проведению чемпионата мира по футболу в 2018 г. в ФКУЗ «Ростовский-на-Дону противочумный институт» Роспотребнадзора оперативно была разработана программа повышения квалификации «Биологическая безопасность работ при выявлении боль- ного/подозрительного на заболевание инфекционными болезнями, вызванными ПБА неустановленного систематического положения», объемом 36 ч.

Эта программа предназначена для специалистов МБУЗ «ГБ № 1 им. Н.А. Семашко» г. Ростова-на-Дону, которое было определено для развертывания под госпитальную базу, имеет модульный инфекционный блок для оказания экстренной медицинской помощи в круглосуточном режиме с обеспечением готовности к госпитализации больных, в том числе требующих строгой изоляции при подозрении на 00И.

Программа предусматривала освоение теоретического материала не только по вопросам биологической безопасности, но и по оценке внешних и внутренних эпидемиологических рисков, актуальным проблемам природно-очаговой краевой патологии, сигнальным признакам 00И. Проведение практических занятий направлено на отработку навыков по применению средств индивидуальной защиты и обеспечению биологической безопасности проведения срочных клинико-диагностических исследований в условиях модульного инфекционного блока.

В конце цикла была проведена итоговая аттестация в форме собеседования и компьютерного тестирования. Обучены 22 специалиста. Успешное освоение программы врачами различных специальностей (31.08.05 «Клиническая лабораторная диагностика», 31.08.67 «Хирургия», 31.08 .02 «Реаниматология, анестезиология») позволило обеспечить биологическую безопасность при работе с больными/подозрительными на инфекционное заболевание и проведении срочных клинико-диагностических исследований в условиях модульного инфекционного блока при проведении массовых мероприятий.

Сотрудники института разрабатывают новую программу с рабочим названием «Биологическая безопасность при проведении работ с особо опасными инфекциями» объемом 36 ч, направленную на совершенствование фундаментальных и специальных знаний, умений, позволяющих специалистам различных специальностей, как постоянно работающих, так и периодически сталкивающихся или способных столкнуться в своей работе с возбудителями 00И, ориентироваться в вопросах организации бактериологической службы с учетом требований биологической безопасности и охраны труда, а также обеспечения безопасных условий при выявлении больного 00И.

В условиях когда не все специалисты могут полноценно пройти повышение квалификации даже в такой сокращенной форме (36 ч), актуальна разработка программ краткосрочных семинаров для приобретения знаний в соответствии с изменяющейся эпидемической обстановкой, ознакомления с актуальными нормативно-методическими документами. В рамках этих программ необходимо проведение тренингов для отработки необходимых для квалифицированного персонала практических навыков.

Краткосрочные семинары - это программы продолжительностью менее 16 ч, не предусматривающие проведение итоговой аттестации [9]. Традиционными формами семинаров являются обучающие, включающие преимущественно теоретическую часть, которые проводятся преимущественно в образовательных учреждениях; научно-практические - 
для научных работников, имеющих опыт и знания, их цель ознакомление с работами коллег в рассматриваемой теме. В отдельную категорию можно вынести вебинары в режиме онлайн [6].

Опыт проведения семинаров в рамках подготовки к проведению массовых мероприятий и при осложнении эпидемической ситуации показал достаточно высокую эффективность такой формы обучения. В ходе подготовки к проведению чемпионата мира по футболу в 2018 г. разработаны программы консультативных семинаров, реализованные на 16 тематических циклах (в том числе видеоконференции и выездные циклы), продолжительностью 8 ч. Группы слушателей семинаров были сформированы в соответствии с профилем специальности: эпидемиологи Роспотребнадзора, инфекционисты и клинические эпидемиологи лечебнопрофилактических организаций, специалисты лабораторной сети медицинских организаций (МО). Цель семинаров совершенствование профессиональных знаний и компетенций специалистов практического здравоохранения Ростовской области и Роспотребнадзора при решении узких задач по обеспечению биологической безопасности, диагностике актуальных инфекционных болезней и готовности к отражению внутренних и внешних эпидемиологических опасностей (рисков).

Для сотрудников Роспотребнадзора Ростовской области разработана программа «Вопросы биологической безопасности при работе с возбудителями I-II групп патогенности. Эпидемиология и профилактика туляремии, сибирской язвы и другой актуальной природно-очаговой краевой патологии». Учебная программа учитывает актуальную эпидемическую ситуацию в мире и структуру природно-очаговых инфекций региона. Предусмотрено освещение вопросов эпидемиологии, клинических проявлений, профилактики актуальной краевой патологии, такой как чума, сибирская язва, туляремия, крымской геморрагической лихорадки, лихорадки Западного Нила и других природно-очаговых инфекций.

Для специалистов лечебно-профилактических организаций разработана и апробирована программа «Организация и обеспечение противоэпидемической готовности к проведению мероприятий в случае завоза или возникновения ОоИ при проведении массовых мероприятий», освещающая практические вопросы отбора, упаковки и транспортировки материала для клинического и микробиологического исследований, использования СИЗ. На практических занятиях слушатели отрабатывают алгоритм решения ситуационных задач по готовности специалистов к соблюдению правил биологической безопасности при возникновении различного рода внештатных ситуаций.

Отдельно разработана программа «Организация лабораторной диагностики инфекционных болезней, лабораторного контроля объектов окружающей среды при проведении массовых мероприятий». Программа предусмотрена для врачей и биологов лабораторной сети МО и акцентирует внимание на вопросах соблюдения биологической безопасности при проведении лабораторных исследований с необеззараженным материалом и предварительно обеззараженными пробами, особенностях текущей и заключительной дезинфекций.
Каждая из программ включает 2 модуля: теоретический и практический. Теоретическая часть направлена на освоение законодательной, нормативно-правовой и нормативнометодической документации, действующей на территории РФ по профилю специальности, а также по вопросам санитарной охраны территории страны, биологической безопасности, предупреждения и ликвидации чс санитарно-эпидемиологического характера [10]. В практическом модуле особое внимание специалистов направлено на отбор, упаковку и транспортировку биологического материала для исследования, правильность использования СИЗ различных типов («Кварц», Tychem и других аналогов противочумных костюмов), утилизацию и предварительное обеззараживание/обезвреживание медицинских отходов класса Б и В; решение эпидемиологических и бактериологических ситуационных задач с обсуждением последовательности действий сотрудников в соответствии с выполняемыми функциями. Все программы непрерывно актуализируются и реализуются для специалистов системы здравоохранения по мере необходимости.

В связи с осложнением эпидемической ситуации по COVID-19 в 2020 г. специалистами института разработана программа семинара «Биологическая безопасность и обеспечение противоэпидемической готовности медицинской организации в случае заноса или возникновения заболевания, вызванного новым коронавирусом (COVID-19)». Реализация этой программы на базе института позволила подготовить специалистов МО г. Ростова-на-Дону и Ростовской области для проведения мероприятий оперативного реагирования и обеспечить высокий уровень готовности к проведению комплекса санитарно-противоэпидемических (профилактических) мероприятий по биологической безопасности в условиях распространения новой коронавирусной инфекции.

Дальнейшая разработка программ семинаров, в том числе по разделу биологической безопасности с учетом внутренних и внешних эпидемиологических рисков, является актуальной, особенно при учете функциональных обязанностей, выполняемых слушателями циклов. Имеется возможность проведения таких семинаров не только на базе образовательного учреждения, но и других МО.

\section{Зак^ючение}

Опыт проведения образовательных циклов в различных формах в период подготовки к массовым мероприятиям (чемпионату мира по футболу 2018 г., Дельфийским играм в 2019 г.) и анализ результатов работы сотрудников учреждений Роспотребнадзора и медицинских организаций показал, что теоретические знания и практические навыки, полученные в процессе обучения, позволили обеспечить надежную защиту населения при проведении комплекса санитарнопротивоэпидемических (профилактических) мероприятий по обеспечению биологической безопасности. В связи с меняющейся эпидемической обстановкой в стране и мире (появление новых и возможное возвращение старых инфекционных болезней) существует необходимость разработки актуальных учебных программ, внедрения новых форм обучения и регулярной оперативной их модернизации. 


\section{СВЕАЕНИЯ ОБ АВТОРАХ}

ФКУЗ Ростовский-на-Дону противочумный институт Роспотребнадзора, Ростов-на-Дону, Российская Федерация:

Сизова Юлия Владимировна (Yulia V. Sizova)* - кандидат биологических наук, старший научный сотрудник отдела профессиональной переподготовки и повышения квалификации специалистов

E-mail:yuisa@mail.ru

https://orcid.org/0000-0002-7831-7767

Бурлакова Ольга Спартаковна (Olga S. Burlakova) - кандидат медицинских наук, ведущий научный сотрудник, и.о. начальника отдела профессиональной переподготовки и повышения квалификации специалистов

E-mail: burlakova_os@antiplague.ru

https://orcid.org/0000-0002-0553-0866

Пичурина Наталья Львовна (Nataliya L. Pichurina) - кандидат медицинских наук, ведущий научный сотрудник, и.о. заведующего лабораторией эпидемиологии особо опасных инфекций

E-mail: natasha.pichugina2010@yandex.ru

https://orcid.org/0000-0003-1876-5397

\section{МИТЕРАТУРА}

1. Фелеральный закон от 30 декабря 2020 г. № 492-Ф3 «0 биологи ческой безопасности в Российской Федерации".

2. Практическое руководство по биологической безопасности в лабораторных условиях. 3-е изА. Женева : В03, 2004. 201 с.

3. Биологическая безопасность. Термины и определения / под реА Г.Г. Онищенко, В.В. Кутырева. 2-е изА., испр. и Аоп. Москва : Медицина 2011. 152 c.

4. Попов Ю.А., Малюкова Т.А., Тихомирова ^.А., Кутырев В.В. Система подготовки специалистов по биологической безопасности в Российской Фелерации // Инфекционные болезни: новости, мнения, обучение. 2016. № 1. С. 11-18.

5. Безопасность работы с микроорганизмами I-ІІ групп патогенности (опасности): СП 1.3.3118-13 // Бюмюютень нормативных и метоАических Аокументов ГоссанэпиднаАзора. 2013. № 3. С. 95-115.

6. Сизова Ю.В., Бурлакова О.С., ^юкшина Е.Ю., Сокольская О.А. Развитие системы подготовки специалистов по холере // Инфекционные болезни: новости, мнения, обучение. 2020. T. 9, № 4. C. 120-125. DOI: https://doi.org/10.33029/2305-3496-2020-9-4-120-125

7. Растунцева Е.В., Тихомирова ^.А., Сазанова Е.В. Пути снижения рисков инфицирования при обучении работе с микроорганизмами I-II групп патогенности (опасности) // Проблемы особо опасных инфекций. 2017. № 3. C. 80-84. DOI: https://doi.org/10.21055/0370-1069-2017-3-80-84

8. URL: http://edu.rosminzdrav.ru/specialistam/vo/\#c543 (дата об ращения: 30.04.2021)

9. Разъяснения об особенностях законодательного и нормативного правового обеспечения в сфере Аополнительного профессионального образования: Письмо Министерства образования и науки Российской Федерации от 7 мая 2014 г. № AK-1261/06.

10. Онищенко Г.Г., Попова А.Ю., Топорков В.П., Смоленский В.Ю., Щербаков С.А., Кутырев В.В. Современные угрозы и вызовы в области биологической безопасности и стратегия противодействия // Проблемь особо опасных инфекций. 2015. №3. С. 5-9.

\section{REFERENCES}

1. Federal Law No. 492-FZ of December 30, 2020 “On Biologica Safety in the Russian Federation". (in Russian)

2. Laboratory biosafety manual. $3^{\text {rd }}$ ed. Geneva: WHO, 2004. 201 p.

3. Biological safety. Terms and definitions. Eds by G.G. Onishchenko, V.V. Kutyrev. $2^{\text {nd }}$ ed., rev. and add. Moscow: Medicine, 2011. 152 p. (in Russian)

4. Popov Yu.A., Malyukova T.A., Tikhomirova L.A., Kutyrev V.V. System of training of specialists in biological safety in the Russian Federation. Infektsionnye bolezni: novosti, mneniya, obuchenie [Infectious Diseases: News, Opinions, Training]. 2016; (1): 11-8. (in Russian)

5. Safety of work with microorganisms of I-II groups of pathogenicity (hazard): SP 1.3.3118-13. Byulleten' normativnykh i metodicheskikh dokumentov Gossanepidnadzora [Bulletin of Normative and Methodical Documents of Gossanepidnadzor]. 2013; 3 (13): 95-115. (in Russian)

6. Sizova Yu.V., Burlakova O.S., Lyukshina E.Yu., Sokol'skaya O.A Development of a system for training cholera specialists. Infektsionnye bolezni: novosti, mneniya, obuchenie [Infectious Diseases: News,
Opinions, Training]. 2020; 9 (4): 120-5. (in Russian) DOI: https://doi. org/10.33029/2305-3496-2020-9-4-120-125

7. Rastuntseva E.V., Tikhomirova L.A., Sazanova E.V. Ways to reduce the risks of infection while training for work with microorganisms of the I-II groups of pathogenicity (hazard). Problemy osobo opasnykh infektsii [Problems of Particularly Dangerous Infections]. 2017; (3):80-4. (in Russian) DOI: https://doi.org/10.21055/0370-1069-2017-3-80-84

8. URL: http://edu.rosminzdrav.ru/specialistam/vo/\#c543 (date of access: April 30, 2021) (in Russian)

9. Clarifi cations on the specifi cs of legislative and regulatory legal sup port in the fi eld of continuing professional education: Letter of the Ministry of Education and Science of the Russian Federation dated May 7, 2014 No. AK-1261/06. (in Russian)

10. Onishchenko G.G., Popova A.Yu., Toporkov V.P., Smolensky V.Yu., Shcherbakova S.A., Kutyrev V.V. Present-day menaces and challenges in the sphere of biological safety and strategy of countermeasures. Problemy osobo opasnykh infektsii [Problems of Particularly Dangerous Infections]. 2015; (3):5-9. (in Russian) DOI: https://doi.org/10.21055/0370-1069-2015-3-5-9

\footnotetext{
* Автор для корреспонденции.
} 


\section{Аоктора меАицинских наук, профессора Р.М. Хаитова}

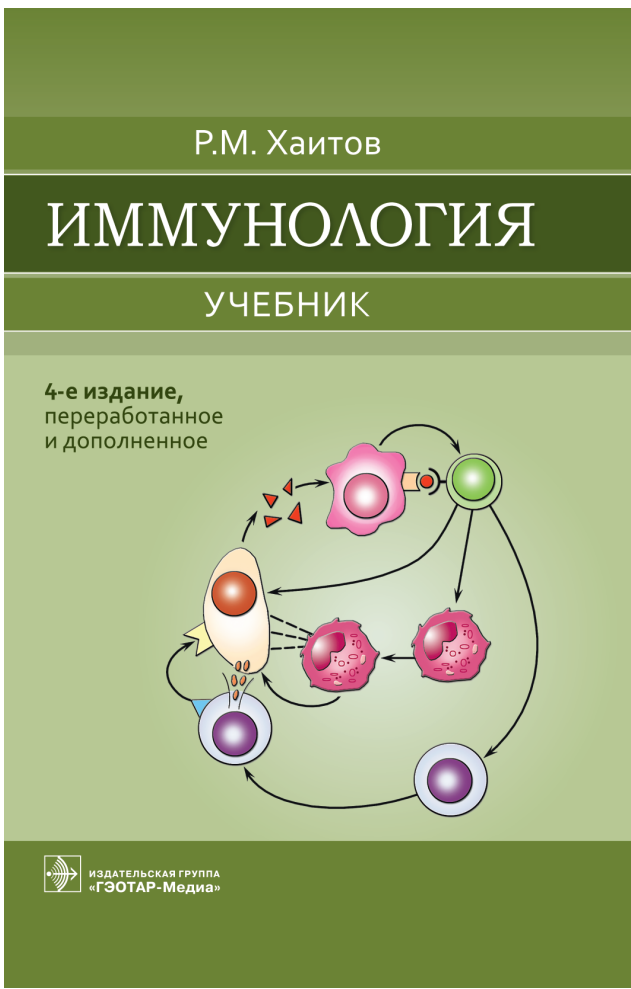

$\mathrm{y}$ чебник «Иммунология», 4-е издание (2021), подготовленный академиком РАН, доктором медицинских наук, профессором Р.М. Хаитовым, представляет собой обновленную, переработанную, дополненную версию и предназначен для использования как в педагогическом процессе медицинских вузов, так и в рамках непрерывного медицинского образования врачей по специальности «клиническая иммунология, аллергология».

Современные представления об иммунитете - это огромный пласт научных сведений. Поэтому учебник должен помогать студентам медицинских или биологических вузов понять и усвоить самое важное, но при этом не утопить обучающихся в изобилии научных фактов, способах их получения, значении этих знаний для понимания функционирования иммунной системы.

Структура переработанного учебника проста и вполне соответствует общепринятому делению иммунологии на разделы. Она включает 3 части, в которых представлен тща- тельно отобранный фактологический материал, дающий представление об основах иммунологии и аллергологии, о возможностях иммунодиагностики, иммунопрофилактики и иммунотерапии. Если первая часть содержит 9 глав, посвященных описанию структуры и функционирования иммунной системы, то вторая часть «Иммунная система и патология»6 объемных глав, в которых с современных позиций рассмотрена патология иммунной системы. Третья часть - приложение, в котором особо следует выделить раздел «Выдающиеся работы, имеющие непосредственное отношение к иммунологии и аллергологии, отмеченные Нобелевскими премиями».

Сведения, представленные в переработанном учебнике, полезны и необходимы не только студентам и аспирантам медицинских вузов, но и преподавателям, врачам и научным сотрудникам, работающим в смежных областях медицины.

Достоинство переработанного учебника - это литературный доступный язык изложения сложных теоретических аспектов иммунологии, широкий, практически всеобъемлющий охват всех областей иммунологии, практическая ориентированность научных знаний, достоверность изложенных сведений, множество иллюстраций, облегчающих понимание и освоение нового материала. На разных иерархических уровнях: молекулярном, клеточном и организменном обобщены представления о факторах врожденного и механизмах формирования адаптивного (приобретенного) иммунитета. Даны сведения о популяциях клеток иммунной системы, рецепторных структурах иммуноцитов, механизмах формирования внутриклеточных сигнальных путей, главном комплексе гистосовместимости, генетическом контроле иммунитета, иммунологической памяти. Подробно описаны иммунодефициты, аллергические и аутоиммунные заболевания. Показана возможность фенотипической коррекции генетического контроля иммунного ответа с помощью иммунотропных лекарственных средств.

В учебнике Р.М. Хаитова для схематизации и упрощения сложных биологических процессов использованы многочисленные графические иллюстрации. Иллюстративный контент удачно адаптирован к восприятию современными студентами и читателями сложной научной литературы. Подписи под рисунками не ограничиваются техническим комментарием и, как правило, поясняют научный аспект иллюстрируемого явления. Пояснения к рисункам и схемам 